\title{
TENDÊNCIAS DA PESQUISA ACADÊMICA SOBRE IDENTIDADE DOCENTE: UMA ANÁLISE DOS ARTIGOS PUBLICADOS NO PORTAL DA CAPES ENTRE OS ANOS DE 2010 A 2014
}

\author{
TRENDS IN ACADEMIC RESEARCH ON TEACHER IDENTITY: AN ANALYSIS OF \\ ARTICLES PUBLISHED IN THE CAPES PORTAL BETWEEN THE YEARS 2010-2014
}

Alisson José Oliveira Duarte ${ }^{1}$ e Helena de Ornellas Sivieri Pereira ${ }^{2}$

\begin{abstract}
RESUMO
O presente trabalho tem por objetivo mapear e discutir as tendências da produção acadêmica brasileira sobre identidade docente, publicadas em periódicos científicos entre os anos de 2010 a 2014, no portal da CAPES. Para tanto, utilizou-se a ferramenta de busca avançada do referido portal para delimitar o tema, onde foram definidos os seguintes critérios de inclusão: "Identidade Docente"; no título dos trabalhos; somente artigos; idioma português; últimos cinco anos. $\mathrm{O}$ resultado da pesquisa apontou 24 artigos, desse total 6 foram eliminados por não atenderem aos objetivos, enquanto 17 foram analisados nesse trabalho. A avaliação qualitativa do material revelou três concepções gerais trazidas pelos autores para explicar o processo de constituição da identidade docente: a visão política, a perspectiva da socialização e a concepção biográfica.
\end{abstract}

Palavras-Chave: Identidade docente. Identidade profissional. Tendências da pesquisa acadêmica.

\begin{abstract}
This study aims to map and discuss the trends of the brazilian academic research on teacher identity, published in scientific journals between the years 2010-2014, in the CAPES portal. Therefore, was used the advanced search tool of the portal to delimit the subject, where the following inclusion criteria were defined: "Identity Teacher"; in the title of the works; only articles; portuguese language; last five years. The result of the research showed 24 articles, of the total 6 were eliminated for not meeting the goals, while 17 were analyzed in this work. The qualitative evaluation of the material revealed three general concepts brought by the authors to explain the process of constitution of the teacher identity: the political vision, the perspective of socialization and biographical conception.
\end{abstract}

Keywords: Teacher identity. Professional identity. Trends in academic research

\footnotetext{
${ }^{1}$ Universidade Federal do Triângulo Mineiro - UFTM. Email: alisson-duarte@hotmail.com

${ }^{2}$ Universidade Federal do Triângulo Mineiro - UFTM. Email helena.sivieri@gmail.com
} 


\section{Introdução}

De acordo com Bueno (2002, p.13) "no âmbito dos estudos mais recentes sobre formação de professores é notável a ênfase que se tem posto sobre a pessoa do professor, aspecto este nitidamente ignorado, ou mesmo desprezado, nos períodos anteriores à década de 1980". Nesse sentido, advogamos que o estudo da constituição da identidade docente abre portas para a compreensão de como o professor atua em seu meio, transformando a realidade educacional tanto na interação com seus alunos, como na relação direta com seus pares; assim como sugere Marcelo (2009, p.109): “a identidade se constrói e se transmite”, para esse autor a identidade individual constituída no cotidiano e na práxis docente reflete e transforma a identidade coletiva.

Com o intuito de refletir como ocorre processo de constituição da identidade docente, nos propomos no presente trabalho mapear as tendências da pesquisa acadêmica sobre o tema. Desse modo, buscamos investigar o que tem sido pesquisado sobre identidade docente e quais as principais concepções teóricas apontadas pelos autores para explicar a dinâmica constitutiva do fenômeno identitário.

Para tanto utilizamos a ferramenta de busca avançada do portal da CAPES (www.periodicos.capes.gov.br) onde foram definidos os seguintes critérios de inclusão: "Identidade Docente"; no título dos trabalhos; somente artigos; idioma português; últimos cinco anos (entre os anos de 2010 a 2014). Dentro dos parâmetros definidos nessa busca foram encontrados 24 artigos; desse total 6 foram eliminados por não atender aos objetivos dessa pesquisa ou por se tratar de material repetido. Ao fim da primeira avaliação do material, restaram 17 artigos que foram minunciosamente analisados nesse trabalho por meio de sua leitura integral. Dentre esses, um artigo foi publicado no ano de 2010; cinco foram publicados no ano de 2011; cinco foram publicados no ano de 2012; dois foram publicados no ano de 2013; e quatro foram publicados no ano de 2014.

Os trabalhos foram inicialmente classificados pelo tipo de identidade tratada ao longo de suas discussões teóricas. Entre as categorias docentes mais abordadas destacam-se os estudos em torno da identidade dos professores de línguas, química, educação física, educação infantil e biologia da modalidade $\mathrm{EaD}$, conforme tabela: 


\begin{tabular}{|l|c|}
\hline \multicolumn{1}{|c|}{ IDENTIDADES ABORDADAS } & QUANTIDADE DE TRABALHOS \\
\hline Professores de línguas: (português, espanhol, inglês e alemão) & 4 \\
\hline Química & 2 \\
\hline Educação Física & 2 \\
\hline Educação Infantil & 1 \\
\hline Biologia EAD & 1 \\
\hline Sem categoria & 7 \\
\hline
\end{tabular}

Fonte: dados elaborados pelos autores (2015).

No próximo tópico, descrevemos os resultados da análise de cada um dos periódicos científicos avaliados, com o objetivo de destacar e classificar as teorias gerais utilizadas pelos autores para explicar o processo de constituição da identidade docente. Lembrando que não nos interessa nesse momento os referenciais (ou expoentes) utilizados pelos autores estudados, mas as abordagens priorizadas por eles.

\section{ANÁLISE DO MATERIAL COLETADO}

Durante a análise do material dessa pesquisa, interessou-nos a visão geral trazida pelos autores para explicar como ocorre o processo de constituição da identidade docente. Para tanto, separamos os trabalhos analisados em três grupos de acordo com a abordagem estabelecida pelos autores como fator constitutivo da identidade docente; a perspectiva política, social e biográfica (ou sócio-afetiva), conforme tabela:

\begin{tabular}{|l|c|}
\hline \multicolumn{1}{|c|}{ TEMAS CONVERGENTES: } & QUANTIDADE DE TRABALHOS \\
\multicolumn{1}{|c|}{ Fatores de influência sobre a identidade docente } & \\
\hline $\begin{array}{l}\text { Políticas Educacionais; Parâmetros Curriculares Nacionais; adaptação } \\
\text { aos parâmetros do Estado. }\end{array}$ & \\
\hline $\begin{array}{l}\text { Interações sociais; experiências relacionais; contextosocial; } \\
\text { Representações sociais. }\end{array}$ & \\
\hline Processo histórico; Elementos biográficos; Dimensãosócio-afetiva. & 5 \\
\hline
\end{tabular}

Fonte: dados elaborados pelos autores (2015).

O primeiro grupo de trabalhos, (quatro artigos), tratam o processo de constituição da identidade docente dentro de uma perspectiva na qual se avalia as políticas públicas educacionais e os parâmetros curriculares nacionais como atravessamentos significativos que podem favorecer (ou inibir) a formação identitária do professor (Araújo; Ferreira, 2011); (Ferreira, 2011); (Pardal, et al, 2011); (Dutra; Terrazzan, 2012).

Araújo e Ferreira (2011) sustentam que a identidade docente na modernidade tem sido fabricada pelas políticas públicas por meio da imposição dos Parâmetros Curriculares Nacionais (PCN's). De acordo com os autores o “discurso oficial em questão, é parte de uma 
política de representação que tem construído uma nova identidade para o professor da educação básica” (p. 103). Os profissionais que não conseguem se adaptar às condições impostas são constantemente afetados pelo estresse e pela ansiedade. Nesse sentido, os referidos parâmetros são concebidos pelos autores como uma violência simbólica e sistêmica que domina os sujeitos com seus discursos situados em uma relação de poder (pelo Estado, dentro das instituições e pelos agentes que os animam).

Ferreira (2011) afirma que as identidades docentes, bem como as representações a elas associadas, são frutos do sistema e a nação que as criou; ou seja, para a autora, o Estado "molda" o professor conforme seus interesses e anseios de uma comunidade idealizada. Nesse sentido, as identidades docentes vão sendo criadas de forma articulada com as transformações do próprio Estado.

Pardal, et al (2011) em seus estudos, destaca duas abordagens amplas que caracterizam as pesquisas em torno do tema identidade docente: a cultural, que evidencia os significados conferidos pelos indivíduos por meio da relação com seus pares "e a político-institucional, que privilegia as formas oficiais de gestão da identidade dos professores, pondo em destaque o papel histórico do Estado como produtor de identidades dos professores" (p.420). A primeira perspectiva pode ser vista como uma fonte de experiências e significados com os quais o indivíduo é afetado em sua identidade conforme assimila os significados e ao mesmo tempo se diferencia na convivência com o outro. A segunda abordagem leva em consideração o constructo identitário a partir dos padrões estabelecidos pelos discursos oficiais ou idealizados pelo Estado (regulamentos, legislações, parâmetros curriculares, serviços e discursos públicos).

Dutra e Terrazzan (2012) sustentam que a identidade profissional de professores é resultante de um processo fortemente marcado pelas "relações que eles mantêm com sua formação e com o sentido que eles conferem ao seu trabalho" (p.173). Por outro lado, analisando a "organização das atuais configurações curriculares de cursos de licenciatura de instituições de ensino superior do país, a partir das normativas legais em vigor” (p.170) buscaram compreender os possíveis reflexos dessas forças legais sobre a formação da identidade de professores da educação básica.

Para os autores os "documentos que orientam a organização dos cursos de licenciatura deveriam contemplar de modo mais claro as atividades a serem desenvolvidas no âmbito das disciplinas" (p.179) sugerindo os pontos técnicos que deveriam ser focalizados na vivência prática dos professores com seus alunos. 
Por outro lado, oito dos trabalhos avaliados, focalizam as teorias da socialização para explicar o processo de constituição da identidade docente. Esses autores refletem as condições de espaço e tempo (o ambiente, as condições sociais, as representações culturais, as instituições e os grupos) como fatores determinantes da identidade docente (Morgado, 2011); (Sá, 2011); (Rodrigues; Figueiredo, 2011); (Sales; Chamon, 2011); (Costa; Rezende, 2014); (Schmidt, 2014); (Iza, et al, 2014); (Beja; Rezende, 2014).

Morgado (2011) reflete o presente tema a partir da profissionalização docente, que para ele "deve promover, em simultâneo, a apropriação de uma dada cultura profissional por parte dos formandos e favorecer a construção de sua identidade profissional” (p.796). Ou seja, além do saber profissional, "a profissionalização contribui, também, para que o futuro professor desenvolva uma identidade" (p.798), uma vez que permite apropriar-se da cultura, dos valores e práticas características da profíssão.

No entanto, ressalva que o desenvolvimento da identidade docente "não pode concretizar-se à margem da diversidade de relações que estabelece com os seus pares" (p.798). Os elementos grupais são fundamentais no processo de identificação dos professores com determinadas características, conferindo-lhes o sentimento de pertença a uma dada categoria. Nesse sentido o autor defende que a identidade deve ser vista como parte essencial da dinâmica pela qual os indivíduos assimilam os elos (visíveis, diretivos ou não) que os mantêm unidos.

Sá (2011) aponta que o fenômeno da identidade docente pode ser analisado por vários ângulos (sociologia, psicologia, antropologia, etc). De acordo com essas vertentes, a identidade do professor tem sido pensada como fluida e múltipla, ao contrário de como era vista como fixa e unificada. "Entendida como um processo, a identidade em sua concepção contemporânea associa-se à compreensão de um sujeito também complexo e múltiplo, cuja atuação no mundo é igualmente multíplice" (p.45). Considera que o constructo identitário ocorre a partir das interações, mediadas pela linguagem, fato que não pode separar-se de seu aspecto relacional ou sociocultural. Sendo a identidade constituída nas práticas discursivas que os indivíduos mantêm uns com os outros, deve-se considerar igualmente o seu caráter dinâmico, combinado e ambíguo, uma vez que as relações sociais colocam em contradição (ou em sintonia) as diferentes identidades que se tocam e se atualizam de modo dialético.

Rodrigues e Figueiredo (2011) refletem a constituição da identidade docente a partir das diversas experiências de socialização vivenciadas pelo professor antes e depois de 
sua formação acadêmica. Para eles a identidade não é algo estanque que se consolida e permanece em um determinado contexto ou época, "mas sim um processo contínuo influenciado pelas vivências de cada sujeito" (p.66), em suas experiências pessoais, acadêmicas, nas organizações, na relação com outros professores e alunos. Para os autores todos os indivíduos são governados por múltiplas pertenças sociais, por essa razão fala em identidades, no plural, até mesmo para levar em consideração o amplo leque de identificações e de socialização possíveis para todos os sujeitos.

A comunicação é ressaltada como outro elemento fundamental no processo de socialização, especialmente a linguagem oral, com a qual o indivíduo tem acesso às representações sociais e significados históricos em relação a todos os tipos de fenômenos sociais e culturais, incluído o sentido das profissões. Na confluência dos aspectos referidos, os autores caracterizam a identidade docente como uma das identidades que constituem o sujeito, pois de acordo com eles, essa é tão somente um campo que evidencia as múltiplas pertenças do indivíduo.

Para Sales e Chamon (2011) a identidade de uma forma geral é fruto das interações sociais, especificamente a partir da introjeção ou identificação com a imagem que os outros fazem do indivíduo. "As relações com o outro geram também identidades sociais, isto é, sentimentos de pertença a um grupo com o qual o indivíduo é suscetível de se identificar" (p.187). A esse respeito afirmam que entre as várias identidades sociais do indivíduo, a identidade profissional se ancora frequentemente nas representações culturais, bem como, nos modos e saberes que estão estreitamente ligados à prática profissional do sujeito. Também ressaltam o caráter dual da identidade: o Eu profissional e o Ideal profissional.

O primeiro pode ser definido como "a imagem que o indivíduo construiu de si mesmo na interação profissional (...). Ele pode ser considerado como o produto da imagem que os outros enviam ao sujeito e que ele próprio integrou" (p.188). Por outro lado, o "Ideal Profissional" pode ser caracterizado "como o modelo (ou conjunto de valores e opções adotadas) do bom profissional que o indivíduo quer vir a ser" (p.188). De acordo com as referidas pesquisadoras, essas duas dimensões da identidade profissional podem ser geradoras de uma crise de identidade, uma vez que os professores têm que lidar com as contradições entre um eu real (aquele que vivenciam realmente nas escolas) e o eu ideal (aquele que eles almejam alcançar ou desenvolver).

Costa e Rezende (2014) defendem que a formação da identidade docente ocorre dentro de um contexto relacional do professor desde a sua formação inicial. Para fundamentar suas 
proposições as autoras criticam e questionam a formação de professores na modalidade $\mathrm{EaD}$; sugerindo que apesar do modismo das relações virtuais, essas ainda não podem ser comparadas com a proximidade humana no sentido da participação mútua, das identificações que só podem ser alcançadas por meio do convívio e da troca de experiências. As autoras ainda salientam que o processo constitutivo da identidade ocorre dentro de um processo linguístico, ou seja, relacional, e ao mesmo tempo dentro de um mecanismo forjado na diferença e reelaborado pelos processos de exclusão/diferenciação.

De acordo com Schmidt (2014) o ser humano é portador da capacidade de simbolizar, com a qual, pode compartilhar significados com seus pares, recriando seus próprios significados à medida que constrói sua singularidade. Entende a constituição identitária como um processo inacabado, multifacetado e híbrido, sujeito a reformulações e manipulações sócio-históricas.

Nesse sentido compreende que a identidade se forma ao longo de um processo psicológico inconsciente permanente, ou seja, em constante construção, não sendo possível sua fixação, uma vez que a identidade pode ser reposicionada em diferentes contextos. A autora ainda ressalta o valor da linguagem como mediadora da constituição da identidade, uma vez que é por meio dela que os indivíduos irão se relacionar. Para ela "a identidade se constrói na interação entre o eu e a sociedade, de forma indissociável" (p.142). Nessa perspectiva, o constructo identitário é caracterizado por um processo polifônico e multirreferencial, continuamente reformulado no viés de uma multiplicidade de vozes sociais do presente e do passado. A identidade por "ser sempre relacional, é feita daquilo que o(s) outro(s) não é, ou seja, a identidade está em constante relação com o outro e entende-se que seja marcada pela diferença" (p.142).

Iza, et al (2014) entendem o constructo identitário dentro de um processo social historicamente situado. Para elas a profissão docente "se constrói com base na significação social da profissão, de suas tradições e também no fluxo histórico de suas contradições" (p.275), destacando ao mesmo tempo, que o desenvolvimento da identidade se dá em determinados contextos como resposta ás demandas e necessidades impostas pela sociedade.

Nesse sentido, as autoras, veem a identidade como um conjunto organizado de saberes, normas e valores que denotam a imagem individual ou coletiva dos professores. Constituir-se como professor pode ser um longo processo, pois demanda assimilar a formação, para atuar, tomar decisões e se reconhecer como formador de futuras gerações. Para elas "a experiência é compreendida como algo que nos acontece, nos passa e nos toca, ou seja, tudo o que 
vivenciamos é capaz de nos transformar e de nos deixar marcas" (p.285). Encerra suas reflexões, afirmando que a identidade continua a se constituir ao longo do exercício profissional, não se limitando às concepções e práticas adquiridas durante a formação inicial. Aliás, chega afirmar que a vida familiar, as representações sociais e as experiências escolares anteriores do professor são muitas vezes mais significativas e formadoras de uma identidade do que a própria formação inicial.

Beja e Rezende (2014) sugerem que a identidade docente é compreendida como uma construção sociocultural, inter-relacionada com inúmeros determinantes (a formação escolar, a relação estabelecida com os professores, as representações sociais, as relações familiares e as vivências nas instituições). Para elas, a construção da identidade docente "é sempre um processo complexo e sustentado pela adesão a determinados princípios e valores, pela ação e pela autoconsciência, uma vez que é no processo de reflexão sobre a sua prática que o professor vai construindo a sua identidade" (p.159). Ainda a esse respeito, explicita que a identidade profissional do professor é construída "a partir da significação social da profissão; da reelaboração contínua dos significados sociais da profissão; da revisão das tradições e da ratificação de posturas e práticas há muito estabelecidas e que continuam significativas" (p.159). Adverte, no entanto, que "a identidade não é um dado acabado, mas sim elaborada na e pela linguagem, nas interações com o outro, de forma relacional e sempre motivada pela diferença" (p.159), não deixando de considerar o fator relacional como central no processo de constituição da identidade docente.

Por fim, cinco dos artigos analisados refletem o processo de constituição da identidade docente dentro de uma perspectiva sócio-afetiva com enfoque na biografia dos professores, o que de certa forma se insere na perspectiva da socialização, no entanto, ao mesmo tempo, se difere por levar em consideração as experiências significativas ou carregadas de afeto como realmente potenciais à constituição da identidade docente. Ou seja, no processo de constituição da identidade docente não basta se relacionar e viver experiências, as relações devem ser significativas para o sujeito (Wachs, 2010); (Nakagome, 2012); (Knoblauch; Torales, 2012); (Rodrigues et al, 2012); (Arnosti et al, 2013).

Wachs (2010) em seus estudos sobre o processo de constituição da identidade docente reflete que identidade pressupõe autoconhecimento, capacidade de perceber-se e de tornar-se consciente de si mesmo. Para ele a "identificação da identidade se dá especialmente através do processo narrativo" (p.194), pelo qual ao narrar sua história pessoal, o professor tende a elaborar um duplo caminho, de retrospecção e prospecção. No entanto, o processo de 
ressignificação da identidade docente não pode se restringir à reflexão crítica da história de vida do professor. "O processo narrativo tem a intenção de ajudar a pessoa do docente a conhecer-se melhor para prescrever a dimensão de sua identidade pessoal e profissional de uma maneira mais consciente e autônoma" (p.194). De acordo com o autor, os professores, ao narrar a suas práticas educativas podem ser levados a um processo de reflexão sobre si mesmo, passando a se conhecer melhor. "O autoconhecimento vai sendo aprimorado quando a pessoa é estimulada ao exercício de organizar e reorganizar o seu pensamento para poder descrever a sua prática educativa" (p.195). Dessa forma, a narração não se trata de uma mera apresentação de fatos, mas um processo pelo qual, o professor interpreta e organiza sua experiência pessoal. "A pessoa que narra seleciona detalhes, excluindo ou incluindo aspectos considerados mais ou menos importantes e esse processo já implica, por si só, uma atividade de reinterpretação" (p.205).

Nakagome (2012) partindo de uma visão sócio-histórica, afirma que o constructo identitário é permanentemente marcado pela (re)elaboração. "Isso permite pensar a identidade como um conceito plural" (p.207), sendo mais apropriado usar o termo identidades, já que esse reserva a dinamicidade como principal característica do processo. Nesse sentido, “o caráter dinâmico da identidade indica que o professor deve ser entendido por sua trajetória passada e sua potencialidade futura, abrangendo-o como um sujeito pleno" (p.208). A autora observa o fenômeno identitário sob uma dupla feição individual e coletiva - a esse respeito, ela explica que dar aulas é uma tarefa solitária, “já que apenas um sujeito se encarrega da condução das atividades.

Mas, ao mesmo tempo, a preparação e avaliação realizadas fora da aula podem ser desenvolvidas com maior segurança quando isso é feito junto ao grupo de trabalho" (p.211), que por sua vez, contribui com a diversidade de olhares. Individuo e grupo, se interrelacionam e se modificam mutuamente nesse processo. Adverte que embora os fatores sociais, políticos e econômicos também possam afetar a formação identitário dos professores, não podemos criar uma relação entre as precárias condições de trabalho e uma possível crise de identidade, porque, também não podemos afirmar que uma melhora das condições de trabalho por si só possam garantir a solidificação positiva de uma identidade profissional.

Knoblauch e Torales (2012) contribuem com a concepção de que a identidade docente está intrinsecamente ligada ao processo histórico/biográfico dos professores, mais que sua formação acadêmica propriamente dita. Para eles, o uso das histórias de vida dos professores objetiva a uma concepção de sujeito integral, considerando os 
acontecimentos sociais, históricos e as limitações que as relações de poder, como de classe, raça e gênero, impõem sobre suas opções pessoais. Dessa forma, narrar a própria biografia, leva os indivíduos a um processo de autoconhecimento, pelo qual o indivíduo se localiza no tempo e no espaço, revendo-se desde a infância até o presente momento. De acordo com as autoras "a estrutura temporal da consciência se define pelo significado que cada pessoa atribui às suas próprias experiências" (p.855). Nesse sentido, elas atestaram por meio de pesquisa de campo que os professores ao serem submetidos ao procedimento de narrativa da própria história, tendem inconscientemente a contextualizar com mais ênfase os aspectos mais significativos ou constituintes de sua identidade, enquanto outras características eram descritas com brevidade ou sequer eram mencionadas.

Conforme Rodrigues et al. (2012) a formação da identidade é fruto de um processo de sucessivas socializações, com as quais o indivíduo toma consciência de sua identidade para si e para outro. A partir das experiências socioprofissionais do professor a formação da identidade "não pode mais ser pautada pela interiorização do social, pois entra em cena a autenticidade" (p.179) dos sujeitos, que vivenciam e elaboram suas experiências de maneira intrinsecamente particular. Os autores ressaltam que "a construção de identidades docentes envolve processos atrelados às trajetórias sociais vivenciadas, pois, muitas vezes, naturalizamos nosso olhar e deixamos de perceber que nossas experiências socioprofissionais, diariamente, nos (trans)formam" (p.181).

Em se tratando da relação dos professores inseridos nas instituições, afirma que "as posições sociais que cada sujeito assume dentro da instituição contribuem com a construção de identidades, pois refletem lugares e representações sobre os sujeitos inseridos em um mesmo espaço, p.186". Assim, nos processos relacionais o sujeito ao conviver com o outro também se relaciona com os significados e representações desse outro para si mesmo. Em uma "sociedade múltipla, o indivíduo se destaca pelo distanciamento em relação ao sistema e pela capacidade de iniciativa e de escolha ao interiorizar o social” (p.179).

Arnosti et al. (2013) compreendem que a formação da identidade é "uma construção histórico-social que perpassa o processo de socialização, as experiências e vivências pessoais e profissionais" (p.9) do professor. Nesse processo um dos principais fatores ressaltados pelos autores é a afetividade, que para eles cumpre um papel central nas interações humanas; aliás, investigando a dimensão (sócio)afetiva dos professores chega a conclusão de que ela pode em muitos casos ser um fator constituinte da identidade docente. 
As interações sociais são marcadas qualitativamente pela afetividade e são estabelecidas desde a socialização primária (contato com os familiares mais íntimos), à socialização secundária (quando as relações se tornam mais complexas e alargadas). Os autores sugerem que os ambientes e as situações são igualmente determinantes na constituição da identidade docente, para tanto, exemplifica que "a redução do apoio dos pais aos filhos em relação aos estudos é uma característica do século XX que pode acarretar mudanças na identidade docente" (p.11), uma vez que os professores em sua dimensão afetiva sentem certa obrigação moral em ter uma preocupação maior com alunos que passam período integral nas escolas. Por outro lado, a relação com os pares também favorece a construção da identidade docente, "na medida em que possibilita a consolidação de espaços de formação mútua, onde todos podem assumir a função de formador e formando" (p.20).

Nenhum artigo destacou a formação acadêmica ou continuada do professor como fator exclusivamente determinante sobre a identidade docente, mas como fator coadjuvante entre uma diversidade de atravessamentos que permeiam o referido processo.

\section{CONSIDERAÇÕES FINAIS}

De acordo com as reflexões levantadas ao longo dessa pesquisa, observamos que entre os anos de 2010 a 2014, os autores que pesquisaram o tema "Identidade Docente" seguiram a tendência de três linhas gerais para explicar o fenômeno da constituição da identidade docente.

A primeira delas se caracteriza pelo predomínio da concepção de que a identidade docente pode ser produzida pelas normativas oficiais (ou seja, pelas políticas educacionais, pelos parâmetros curriculares e pelo Estado). Consideramos tal perspectiva limitada para dar conta da complexidade do fenômeno identitário e discordamos que os discursos oficiais em questão sejam capazes de produzir, por si só, representações políticas suficientemente dominadoras para moldar a identidade docente ou padronizá-la como se os professores fossem sujeitos passivos e despersonalizados frente às imposições legais.

Essa abordagem leva em consideração o momento político (presente) vivenciado pelos professores como fator constitutivo da identidade profissional, não levando tanto em consideração - embora, alguns estudos tenham citado com menor ênfase - as experiências anteriores do professor com seus pares, alunos, suas vivências e sua história pessoal. 
No entanto, não desconsideramos de modo algum, que as normativas oficiais e os parâmetros curriculares sejam formas políticas de dominação que podem evidentemente oferecer entraves (angústias, patologias e limitações) no exercício da profissão docente. Nesse sentido, sugerimos que a influência política do Estado não seja um fator exclusivamente determinante sobre a identidade docente, mas um fator coadjuvante entre uma diversidade de atravessamentos que permeiam o referido processo.

Diferente do último bloco, os autores que explicitam o processo de constituição da identidade docente sob a perspectiva das relações sociais, consideram uma quantidade maior de fatores ao avaliar a complexidade do fenômeno identitário (o ambiente, as condições sociais, as representações culturais, as instituições, os grupos, o espaço e o tempo).

A comunicação é ressaltada como elemento fundamental no processo de socialização, especialmente a linguagem oral, com a qual o indivíduo tem acesso às representações sociais e significados históricos em relação a todos os tipos de fenômenos sociais e culturais, incluído o sentido das profissões.

Nessa abordagem, as diferentes dimensões e experiências relacionais do sujeito são concebidas de maneira estreitamente interligada, de modo que o indivíduo é visto como fruto de um processo interacional dinâmico, formado por identidades (no plural), uma vez que ao longo de sua história transforma e transmite sua identidade nas trocas interpessoais.

Por último, entre todas as pesquisas analisadas, consideramos a perspectiva biográfica ou sócio-afetiva, como aquela que mais se destacou em termos de consistência teórica. Embora, não tenha aparecido em maior quantidade de trabalhos, destacou-se pela complexidade e amplitude ao lidar com o tema.

Assim como nos referimos anteriormente, essa concepção de certa forma se insere na perspectiva da socialização, no entanto, ao mesmo tempo, se difere por levar em consideração as experiências afetivas na história de vida dos professores, como elemento potencial no processo de constituição da identidade docente. O diferencial dessa abordagem, em relação à refletida anteriormente, é o fato de levar a afetividade e o significado pessoal das experiências com mais ênfase do que a experiência propriamente dita. Nela o sujeito não é apenas fruto das relações externas, mas da dinâmica entre os mundos interno e externo. Para esses estudos a afetividade confere o valor qualitativo às experiências, sem o qual, as relações sociais não exerceriam qualquer efeito psicológico sobre a identidade do indivíduo. Nesse sentido, o que fixa a experiência e transforma a identidade, é o valor qualitativo (emocional) e o significado intrínseco conferido a ela. 
Mediante os resultados obtidos, nessa pesquisa, advogamos a necessidade de investir em estudos, nos próximos anos, voltados à compreensão do constructo identitário dentro da complexidade sócio-afetiva, ressaltando-a como elemento mediador do processo de internalização das experiências sociais vivenciadas pelos indivíduos nas diferentes dimensões. Conquanto, consideramos que sua amplitude garante a diversidade e complexidade psicológica do fenômeno identitário.

\section{REFERÊNCIAS}

ARAÚJO, Alex Pereira de; FERREIRA, Élida Paulina. A identidade em parâmetros curriculares: em questão a subjetividade do professor de português. Revista Eletrônica de Educação. São Carlos, SP: UFSCar, v. 5, no. 2, p.96-123, nov. 2011.

ARNOSTI, Rebeca Possobom; et al. Profissão Professor: a dimensão afetiva contemplada em sua identidade. Rio Claro, Educação: Teoria e Prática, Vol. 23, n.44, p. 04-23, Dez, 2013.

BEJA, Ana Carla; REZENDE, Flávia. Processos de construção da identidade docente no discurso de estudantes da licenciatura em química. Revista Electrónica de Enseñanza de las Ciencias v. 13, n. 2, (p.156-178), 2014.

BUENO, Belmira Oliveira. O método autobiográfico e os estudos com histórias de vida de professores: a questão da subjetividade. São Paulo: Rev.Educ. Pesqui, 2002.

COSTA, Mara Lúcia Rodrigues; REZENDE, Flávia. Construção da identidade docente de um estudante de licenciatura em Ciências Biológicas em curso a distância: um caso de hibridismo. Belo Horizonte, Revista Ensaio, v.16, n. 01, p. 149-169, abril, 2014.

DUTRA, Edna Falcão; TERRAZZAN, Eduardo Adolfo. Reflexos das normativas legais sobre a formação de professores da educação básica em configurações curriculares de cursos de licenciatura em química e formação da identidade. Belo Horizonte, Rev. Ensaio, v. 14, n. 01, p.169-180, abril, 2012.

FERREIRA, Márcia Ondina Vieira. Construção de identidades docentes: entre a vocação, as necessidades objetivas e os processos sociais. Porto Alegre, Pontifícia Universidade Católica do Rio Grande do Sul, Rev. Educação, vol. 34, núm. 1, pp. 106-113, abril, 2011.

FERREIRA, Norma Sandra de Almeida. As Pesquisas denominadas "Estado da Arte". São Paulo, Educação \& Sociedade, ano XXIII, no79, Agosto, 2002. 
IZA, Dijnane Fernanda Vedovatto; et al. Identidade docente: As várias faces da constituição do ser professor. São Carlos, Revista Eletrônica de Educação, v. 8, n. 2, 2014. Disponível em: http://www.reveduc.ufscar.br

KNOBLAUCH, Adriane; TORALES, Marília Andrade. Pesquisas sobre identidade e socialização docente: ação e formação nas imbricações biográficas dos professores. Paraná, Pontifícia Universidade Católica, Revista Diálogo Educacional, vol. 12, núm. 37, pp. 843862, dezembro, 2012.

MARCELO, Carlos. A identidade docente: constantes e desafios. Belo Horizonte: Revista Brasileira sobre formação de Professores, v. 01, n. 01, p. 109-131, agosto, 2009.

MORGADO, José Carlos. Identidade e profissionalidade docente: sentidos e (im)possibilidades. Ensaio: aval. pol. públ. Educ., Rio de Janeiro, v. 19, n. 73, p. 793-812, dez, 2011.

NAKAHOME, Patrícia. Identidade docente em formação. São Paulo, Linha d'Água, n. 25 (1), p. 203-217, 2012.

PARDAL, Luís; et al. Quando for grande vou ser professor: a identidade docente representada por futuros professores. Pontifícia Universidade Católica do Paraná, Revista Diálogo Educacional, vol. 11, núm. 33, pp. 417-433, agosto, 2011.

RODRIGUES, Renata Marques; FIGUEIREDO, Zenólia Campos. Construção identitária da professora de Educação Física em uma instituição de educação infantil. Porto Alegre, Movimento, v.17, n.04, p.65-81, dez, 2011.

RODRIGUES, Renata Marques; et al. Relações socioprofissionais como elemento de influência na construção das identidades docentes. Porto Alegre, Rev. Movimento, v. 18, n.04, p.175-195, dez, 2012.

SÁ, Elisa Mattos de. O professor de inglês para negócios: reflexos de uma identidade em construção. Porto Alegre, BELT Journal, v.2, n.1, p 43-58, junho, 2011.

SALES, Adriane de Castro Menezes; CHAMON, Edna Maria Querido de Oliveira. Escolha da carreira e processo de construção da identidade profissional docente. Belo Horizonte, Educação em Revista, v.27, n.03, p.183-210, dez, 2011.

SCHMIDT, Cristiane. Identidade do professor e do aprendiz de língua alemã: Um levantamento eletrônico de alguns estudos brasileiros. São Paulo, Rev. Expectativa, $\mathrm{n}^{\circ} 13$, V.13, 2014. 
WACHS, Manfredo Carlos. As dinâmicas simbólicas e a (re)construção da identidade docente. Porto Alegre, Teocomunicação, v. 40, n. 2, p. 192-212, ago, 2010.

RECEBIDO EM: 03/03/2016

APROVADO PARA PUBLICAÇÃO EM: 29/06/2016 